\title{
The Troms $\varnothing$ heart study: coronary risk factors and their association with living conditions during childhood
}

\author{
EGIL ARNESEN AND ANDERS FORSDAHL \\ From the Institute of Community Medicine, University of Troms $\emptyset$, Norway
}

SUMMARY We examined the relation between questionnaire answers concerning living conditions during childhood and coronary risk factors in 7405 men and 7247 women. Poverty during childhood was positively associated with age-adjusted levels $(p<0.05)$ of total cholesterol and percentage of current smokers (men only) and negatively associated with body height. When cholesterol was adjusted for age, body mass index, leisure time physical activity, coffee and alcohol consumption, and cigarette smoking there was a significant linear trend in women $(p \leqslant 0.0001)$ but not in men $(\mathrm{p}=0.224)$. Analysing only subjects born in Troms county, giving a more homogeneous population, the linear trend became significant $(p=0.011)$ for men also. We conclude that $t^{\infty} \dot{\omega}$ childhood poverty followed by a high standard of living operates, at least partly, as a risk factor for $\frac{0}{T} \vec{N}$ coronary heart disease through conventional risk factors.

A positive correlation between mortality in Norwegian counties and infant mortality in the counties of the origin of the deceased subjects has previously been demonstrated, whereas no correlation with present infant mortality was found. ${ }^{1}$ Arteriosclerotic heart disease in both sexes, and lung cancer among men, were the most prominent causes of death. In the cardiovascular survey in Finnmark 1974-5, a corresponding association between cholesterol in both sexes and smoking among men and infant mortality was shown. ${ }^{2}$ Infant mortality was used as an indicator of living conditions; the explanation proposed was that poverty during childhood, followed later by a high 'standard of living', could be regarded as a risk factor for cardiovascular disease. When the latter condition is not fulfilled, as in many of the developing countries, mortality from cardiovascular disease remains low.

The Troms $\varnothing$ heart study carried out in 1979-80 provided the opportunity to examine the relation between risk factors for cardiovascular disease and information about economic conditions during childhood.

\section{Materials and methods}

The population examined consisted of men born between 1925 and 1959 and women born between
1930 and 1959 living in the municipality of Tromsø. Altogether 16621 subjects were screened, 78\% of those invited. The examination comprised administration of a questionnaire identical with thato used in the former study in Troms $\emptyset^{3}$ and the? cardiovascular studies in Norwegian counties ${ }^{4}$; collection of venous nonfasting blood samples for measurements of lipids and glucose levels; and weight, height, and blood pressure measurements. In addition, all participants were given a second questionnaire on dietary habits, alcohol and coffee consumption, and economic conditions during childhood as well as previous diseases. They were instructed to fill in this questionnaire at home and return it by mail.

The 14652 participants who returned the second questionnaire with appropriately filled in answers are the basis for the present analysis. The question concerning living conditions during childhood was, "What were the economic conditions in your family during childhood?" The possible answers were very difficult, difficult, good, and very good.

The response pattern according to age and sex is shown in table 1 . The table reflects the economic development in our society since the late twenties. Only $15 \%$ of the youngest men answered that they had grown up with difficult or very difficult economic conditions, compared with more than $50 \%$ of men 
Table 1 Percentage distribution of answers to the question "What were the economic conditions in your family during childhood?" according to age and sex, Troms $\emptyset$ 1979-80

\begin{tabular}{|c|c|c|c|c|c|c|c|c|c|c|c|c|}
\hline \multirow{3}{*}{$\begin{array}{l}\text { Age } \\
\text { (years) }\end{array}$} & \multicolumn{12}{|c|}{ Percentage distribution } \\
\hline & \multicolumn{6}{|l|}{ Men } & \multicolumn{6}{|l|}{ Women } \\
\hline & Number & Very good & Good & Difficult & Very difficult & No answer & Number & Very good & Good & Difficult & Very difficult & No answer \\
\hline $20-24$ & 851 & $8 \cdot 1$ & $75 \cdot 3$ & $13 \cdot 6$ & $1 \cdot 4$ & 1.5 & 1227 & $10 \cdot 5$ & 73.7 & $13 \cdot 2$ & $1 \cdot 3$ & $1 \cdot 2$ \\
\hline $25-29$ & 1290 & $5 \cdot 4$ & 68.7 & $22 \cdot 9$ & 1.7 & $1 \cdot 3$ & 1542 & $6 \cdot 2$ & $70 \cdot 4$ & 20.4 & $2 \cdot 0$ & $1 \cdot 0$ \\
\hline $30-34$ & 1508 & $4 \cdot 0$ & $61 \cdot 5$ & $30 \cdot 7$ & $2 \cdot 3$ & 1.5 & 1598 & $5 \cdot 0$ & $64 \cdot 2$ & $26 \cdot 3$ & $3 \cdot 5$ & 1.0 \\
\hline $35-39$ & 1246 & 3.0 & $51 \cdot 2$ & $40 \cdot 2$ & $4 \cdot 1$ & 1.5 & 1216 & $4 \cdot 0$ & $60 \cdot 4$ & 30.7 & $4 \cdot 1$ & 0.8 \\
\hline $40-44$ & 892 & $2 \cdot 7$ & 49.7 & $40 \cdot 8$ & $5 \cdot 5$ & $1 \cdot 3$ & 889 & $4 \cdot 8$ & $54 \cdot 3$ & $34 \cdot 6$ & 3.9 & $2 \cdot 3$ \\
\hline $45-49$ & 810 & $3 \cdot 1$ & $48 \cdot 3$ & $41 \cdot 0$ & $6 \cdot 3$ & 1.4 & 775 & $4 \cdot 8$ & 53.6 & 34.9 & $5 \cdot 3$ & 1.4 \\
\hline $50-54$ & 808 & $2 \cdot 7$ & $44 \cdot 3$ & $42 \cdot 0$ & $9 \cdot 3$ & $1 \cdot 7$ & - & - & - & - & - & - \\
\hline $20-49$ & 6597 & $4 \cdot 3$ & $59 \cdot 7$ & $31 \cdot 4$ & $3 \cdot 3$ & 1.4 & 7247 & 6.0 & $64 \cdot 1$ & $25 \cdot 5$ & $3 \cdot 1$ & $1 \cdot 2$ \\
\hline $20-54$ & 7405 & $4 \cdot 1$ & 57.9 & $32 \cdot 5$ & $4 \cdot 0$ & 1.4 & - & - & - & - & - & - \\
\hline
\end{tabular}

aged 50-54 years. Women showed the same trend although for economic conditions they scored higher than the men.

Total cholesterol was measured directly by the enzymatic oxidase method using a commercial kit (Boehringer). High-density-lipoprotein (HDL) cholesterol was assayed by the same procedure after precipitation of lower density lipoproteins with heparin and manganese chloride. Triglycerides were enzymatically determined as glycerol (Boehringer) and glucose by the hexokinase method (Boehringer). All the laboratory assessments were performed by the Division of Clinical Chemistry, University Teaching Hospital of Tromsø.

Age-adjustments were done by the indirect method with the subjects without known diabetes or cardiovascular disease or symptoms suggesting angina pectoris or claudicatio intermittens as reference population. The difference between the adjusted values of those who had grown up with very good and those with very difficult economic conditions was tested by a two sample $t$ test.

One-way analyses of covariance were performed for each sex separately with the BMDPIV program. ${ }^{5}$ The analyses were done with cholesterol and height as dependent variables, economic conditions during childhood as the grouping variable, and the following covariates: age (5-year groups), logarithm of body mass index (weight/height ${ }^{2}$ ), alcohol consumption (yes/no), current cigarette smoking (yes/no), number of cigarettes per day, leisure physical activity (graded 1-4 with increasing activity) and coffee consumption (graded 1-4 with increasing consumption). The difference between categories of economic conditions during childhood was tested for equality of adjusted group means, linear trend, and difference between the extreme groups. Linear trend was tested using contrasts $(-3,-1,1,3)$ between means of adjusted categories.

\section{Results}

Tables 2 and 3 show age-adjusted risk factors according to economic conditions during childhood for men and women aged $20-49$ years, respectively. The differences between the extreme groups in cholesterol, height, and percentage of current smokers are statistically significant $(p<0.05)$ for both sexes, except for women smokers. The differences in cholesterol, however, were greater in women $(0.43 \mathrm{mmol} / \mathrm{l}$ and $2.6 \%)$ than in men $(0.20 \mathrm{mmol} / \mathrm{l}$ and $1.9 \%)$, whereas the opposite trend was demonstrated for height and smoking.

Table 4 shows cholesterol and height according to economic conditions during childhood adjusted by analysis of covariance. The table displays almost the same picture as the indirect age-adjusted values in tables 2 and 3 , except for cholesterol in men where the difference between grouping categories lost statistical significance.

However, when the analyses were made on a more homogeneous population, ie, subjects born in Troms county (table 5), the difference between categories of economic conditions during childhood increases compared to the total population. A statistically significant trend is observed for cholesterol for both sexes and height among men.

\section{Discussion}

A problem arises as to how to validate whether the answers to the question about economic conditions during childhood reflect the degree of poverty during childhood. For example, some people may have 
Table 2 Age-adjusted mean $(\bar{x})$ and standard deviation (SD) of risk factors in 6504 men aged 20-49 years according to economic conditions in family during childhood, Troms $\emptyset 1979-80$

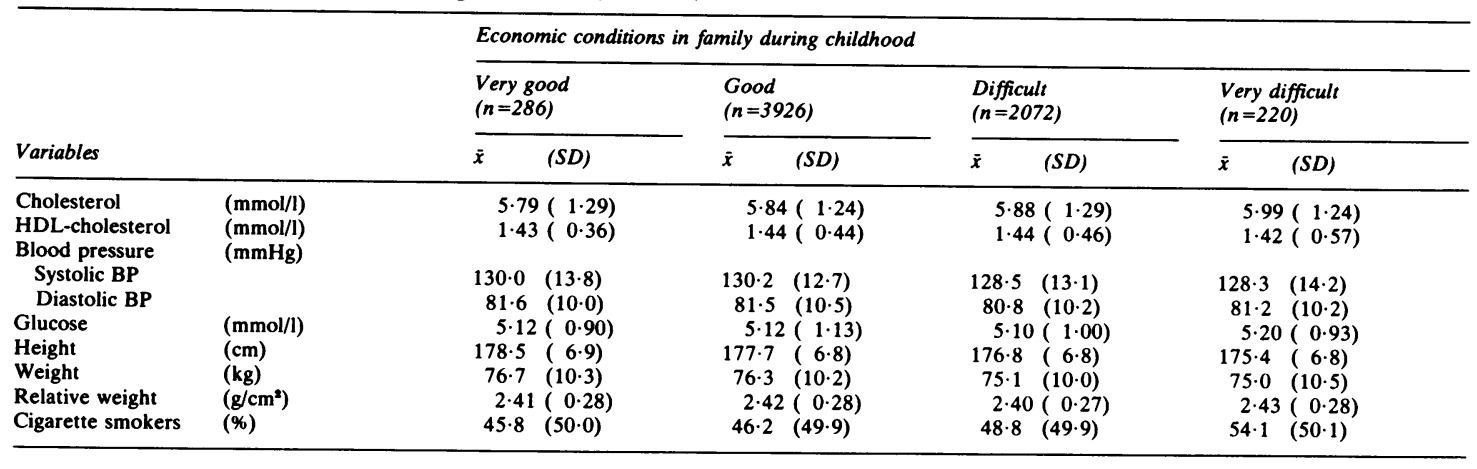

Table 3 Age-adjusted mean $(\bar{x})$ and standard deviation (SD) of risk factors in 7159 women aged $20-49$ years according to economic conditions in family during childhood, Troms $\emptyset 1979-80$

\begin{tabular}{|c|c|c|c|c|c|}
\hline \multirow[b]{3}{*}{ Variables } & & \multicolumn{4}{|c|}{ Economic conditions in family during childhood } \\
\hline & & $\begin{array}{l}\text { Very good } \\
(n=433)\end{array}$ & $\begin{array}{l}\text { Good } \\
(n=4650)\end{array}$ & $\begin{array}{l}\text { Difficult } \\
(n=1847)\end{array}$ & $\begin{array}{l}\text { Very difficult } \\
(n=229)\end{array}$ \\
\hline & & $(S D)$ & $(S D)$ & $(S D)$ & $(S D)$ \\
\hline Cholesterol & $(\mathrm{mmol} / \mathrm{l})$ & $5 \cdot 52(1 \cdot 11)$ & $5.67(1.14)$ & $5 \cdot 71(1 \cdot 20)$ & $5.95(1.32)$ \\
\hline $\begin{array}{l}\text { HDL-cholesterol } \\
\text { Blood pressure }\end{array}$ & $\begin{array}{l}(\mathrm{mmol} / \mathrm{l}) \\
(\mathrm{mmHg})\end{array}$ & $1.74(0.42)$ & $1.75(0.42)$ & $1.73(0.41)$ & $1.71(0.43)$ \\
\hline Systolic BP & & $121 \cdot 2 \quad(12 \cdot 5)$ & $120 \cdot 8 \quad(13 \cdot 3)$ & $120.9 \quad(13.7)$ & $121 \cdot 5 \quad(14 \cdot 1)$ \\
\hline Diastolic BP & & $77.9 \quad(9.3)$ & $77.9(9.7)$ & $78.0 \quad(9.9)$ & $78.4(10 \cdot 0)$ \\
\hline Glucose & (mmol/l) & $5.09(0.70)$ & $5.09(0.83)$ & $5.10(0.90)$ & $5.17(0.77)$ \\
\hline Height & $(\mathrm{cm})$ & $164.9(6.1)$ & $164 \cdot 1 \quad(6 \cdot 1)$ & $163.4(6.2)$ & $163.0(6.4)$ \\
\hline Weight & (kg) & $61.4 \quad(8.8)$ & $60.6 \quad(8.8)$ & $60.7 \quad(9.9)$ & $61.7 \quad(9.8)$ \\
\hline Relative weight & $\left(\mathrm{g} / \mathrm{cm}^{2}\right)$ & $2.26(0.32)$ & $2.25(0.31)$ & $2.27(0.36)$ & $2.31(0.36)$ \\
\hline Cigarette smokers & (\%) & $47 \cdot 2(50 \cdot 1)$ & $45 \cdot 1 \quad(49 \cdot 8)$ & $47 \cdot 5(50 \cdot 0)$ & $49.4(50 \cdot 1)$ \\
\hline
\end{tabular}

Table 4 Adjusted mean $(\bar{x})$ and standard error (SE) of cholesterol ${ }^{*}$ and height ${ }^{\dagger}$ according to sex and economic conditions during childhood, Troms $\emptyset$ 1979-80

\begin{tabular}{|c|c|c|c|c|c|c|c|c|c|c|}
\hline \multirow[b]{3}{*}{ Economic conditions } & \multicolumn{5}{|c|}{ Men 20-54 years } & \multicolumn{5}{|c|}{ Women $20-49$ years } \\
\hline & \multirow[b]{2}{*}{ Number } & \multicolumn{2}{|c|}{ Cholesterol } & \multicolumn{2}{|l|}{ Height } & \multirow[b]{2}{*}{ Number } & \multicolumn{2}{|c|}{ Cholesterol } & \multicolumn{2}{|l|}{ Height } \\
\hline & & $\overline{\boldsymbol{x}}$ & $(S E)$ & $\bar{x}$ & $(S E)$ & & $\bar{x}$ & $(S E)$ & $\bar{x}$ & $(S E)$ \\
\hline $\begin{array}{l}\text { Very good } \\
\text { Good } \\
\text { Difficult } \\
\text { Very difficult }\end{array}$ & $\begin{array}{r}291 \\
4137 \\
2325 \\
281\end{array}$ & $\begin{array}{l}5 \cdot 97 \\
6 \cdot 00 \\
6 \cdot 01 \\
6 \cdot 09\end{array}$ & $\begin{array}{l}(0.07) \\
(0.02) \\
(0.02) \\
(0.07)\end{array}$ & $\begin{array}{l}178 \cdot 0 \\
177 \cdot 4 \\
176 \cdot 7 \\
175 \cdot 0\end{array}$ & $\begin{array}{l}(0 \cdot 4) \\
(0 \cdot 1) \\
(0 \cdot 1) \\
(0 \cdot 4)\end{array}$ & $\begin{array}{r}407 \\
4382 \\
1750 \\
222\end{array}$ & $\begin{array}{l}5 \cdot 49 \\
5 \cdot 65 \\
5 \cdot 66 \\
5 \cdot 89\end{array}$ & $\begin{array}{l}(0.05) \\
(0.02) \\
(0.02) \\
(0.07)\end{array}$ & $\begin{array}{l}164 \cdot 8 \\
164 \cdot 1 \\
163 \cdot 5 \\
163 \cdot 1\end{array}$ & $\begin{array}{l}(0 \cdot 3) \\
(0 \cdot 1) \\
(0 \cdot 1) \\
(0 \cdot 4)\end{array}$ \\
\hline $\begin{array}{l}\text { Total } \\
\text { SD }\end{array}$ & 7034 & $\begin{array}{l}6 \cdot 00 \\
1 \cdot 11\end{array}$ & $(0 \cdot 01)$ & $\begin{array}{r}177 \cdot 1 \\
6 \cdot 7\end{array}$ & $(0 \cdot 1)$ & 6761 & $\begin{array}{l}5 \cdot 64 \\
1.03\end{array}$ & $(0.01)$ & $\begin{array}{r}164 \cdot 0 \\
6 \cdot 1\end{array}$ & $(0 \cdot 1)$ \\
\hline $\begin{array}{l}\text { Test }(p=) \\
\text { Equality } \\
\text { Linear trend } \\
\text { Extreme groups }\end{array}$ & & $\begin{array}{l}0.602 \\
0 \cdot 224 \\
0 \cdot 233\end{array}$ & & $\begin{array}{l}0 \cdot 00 \\
0 \cdot 00 \\
0 \cdot 00\end{array}$ & & & $\begin{array}{l}0.000 \\
0.000 \\
0.000\end{array}$ & & $\begin{array}{l}0.000 \\
0.00 \\
0.00\end{array}$ & \\
\hline
\end{tabular}

*Adjusted for age, alcohol and coffee consumption, relative weight, leisure physical activity, cigarette consumption.

+Adjusted for age only. 
The Troms $\emptyset$ heart study: coronary risk factors and their association with living conditions during childhood 213

Table 5 Adjusted mean $(\bar{x})$ and standard error (SE) of cholesterol ${ }^{*}$ and height ${ }^{\dagger}$ according to sex and economic conditions during childhood for subjects born in Troms County, Troms $\emptyset 1979-80$

\begin{tabular}{|c|c|c|c|c|c|c|c|c|c|c|}
\hline \multirow[b]{3}{*}{ Economic conditions } & \multicolumn{5}{|c|}{ Men 20-54 years } & \multicolumn{5}{|c|}{ Women $20-49$ years } \\
\hline & \multirow[b]{2}{*}{ Number } & \multicolumn{2}{|c|}{ Cholesterol } & \multicolumn{2}{|l|}{ Height } & \multirow[b]{2}{*}{ Number } & \multicolumn{2}{|c|}{ Cholesterol } & \multicolumn{2}{|l|}{ Height } \\
\hline & & $\overline{\boldsymbol{x}}$ & $(S E)$ & $\bar{x}$ & $(S E)$ & & $\overline{\boldsymbol{x}}$ & $(S E)$ & $\overline{\boldsymbol{x}}$ & $(S E)$ \\
\hline Very good & 207 & 5.92 & $(0 \cdot 08)$ & $177 \cdot 2$ & $(0 \cdot 5)$ & 276 & 5.53 & $(0.06)$ & $164 \cdot 1$ & $(0.4)$ \\
\hline Good & 2945 & 6.05 & $(0.02)$ & $176 \cdot 8$ & $(0 \cdot 1)$ & 3075 & $5 \cdot 70$ & $(0.02)$ & $163 \cdot 7$ & $(0 \cdot 1)$ \\
\hline Difficult & 1744 & 6.03 & $(0.03)$ & $176 \cdot 1$ & $(0 \cdot 2)$ & 1255 & $5 \cdot 70$ & $(0.03)$ & $163 \cdot 1$ & $(0 \cdot 2)$ \\
\hline Very difficult & 188 & $6 \cdot 22$ & $(0 \cdot 08)$ & $174 \cdot 6$ & $(0 \cdot 5)$ & 144 & 5.99 & $(0.09)$ & $163 \cdot 0$ & $(0.5)$ \\
\hline Total & 5084 & 6.04 & $(0 \cdot 02)$ & $176 \cdot 5$ & $(0 \cdot 1)$ & 4750 & $5 \cdot 70$ & $(0 \cdot 02)$ & $163 \cdot 5$ & $(0 \cdot 1)$ \\
\hline SD & & $1 \cdot 11$ & & $6 \cdot 7$ & & & $1 \cdot 07$ & & $6 \cdot 1$ & \\
\hline \multicolumn{11}{|l|}{ Test $(p=)$} \\
\hline Equality & & \multirow{2}{*}{\multicolumn{2}{|c|}{$\begin{array}{l}0.057 \\
0.011\end{array}$}} & \multicolumn{2}{|c|}{$0 \cdot 000$} & & \multicolumn{2}{|l|}{0.000} & \multicolumn{2}{|c|}{0.024} \\
\hline Linear trend & & & & $0.0 \mathrm{c}$ & & & 0.000 & & 0.05 & \\
\hline Extreme groups & & \multicolumn{2}{|l|}{0.009} & \multicolumn{2}{|c|}{0.000} & & \multicolumn{2}{|l|}{0.000} & \multicolumn{2}{|c|}{0.090} \\
\hline
\end{tabular}

*Adjusted for age, alcohol and coffee consumption, relative weight, leisure physical activity, cigarette consumption.

tAdjusted for age only.

compared their present situation with the situation during childhood. In the present study, it is not possible to check the subject's scoring, and the magnitude of the bias is difficult to estimate but is likely to be largest in the oldest age group. Other confounding factors are different opinions about poverty among people of different sexes, from different ethnic groups or different parts of the country. These factors, however, can to some extent be adjusted.

Another problem is that the question allows only four groups and that few grouped themselves into the extreme groups. This fact restricts the possibility of looking at different subsamples of the population in order to control for confounding factors or bias.

The fact that subjects who had grown up under difficult conditions during childhood had the lowest body height is in accordance with an hypothesis that these people do not fully utilise their genetic potential. ${ }^{67}$ This is an indirect verification that the question separates the population according to poverty during childhood. The differences between extreme groups were 45 and $28 \%$ of the standard deviation in men and women, respectively. If we use height as an indicator of poverty during childhood, it seems that male subjects give the most proper answer to the 'poverty' question. However, we have to take into account that height may operate differently in the two sexes.

Those who claimed very difficult economic conditions during childhood had the highest risk of coronary heart disease represented by cholesterol and, for men only, smoking. When we adjust cholesterol for confounding factors in men, however, there are only nonsignificant differences.
However, when we restrict our analysis to subjects born in Troms County, giving a more homogeneous population with regard to social and economic conditions during both childhood and adolescence, and exclude a possible "healthy migrant" effect, the differences in cholesterol between groups increased. These findings indicate that the observed elimination of statistically significant differences by adjusting for known confounding factors may be due to bias. Further analyses of more homogenous groups, for example within ethnic groups, were not possible because of the small numbers of subjects in the extreme groups.

In this analysis it is impossible to exclude the possibility that poverty during childhood may operate through another closely correlated variable. Social class or educational level may be such variables. The Oslo study ${ }^{8}$ has demonstrated a clear relation between socioeconomic status and cholesterol for men with the same difference between extreme groups as in this study, whereas the Whitehall study ${ }^{9}$ showed a difference in cholesterol in the opposite direction. However, both studies 910 showed a clear gradient between the extreme classes with regard to both total and cardiovascular death, although the definitions of socioeconomic status were different.

The observed difference in cholesterol level accounts for roughly a $25 \%$ difference in cardiovascular mortality between the extreme groups, based on previous Norwegian studies. ${ }^{11} 12$ The differences in smoking habits indicate an even larger difference in mortality, but it is difficult to give a better guess as to the magnitude of the mortality difference. Taking into account the problems with 
validation of the childhood poverty question, bias and possible confounding factors, it is impossible to explore this question further with our data. Neither can we exclude a possible direct effect on mortality.

Altogether the results are in accordance with higher mortality from cardiovascular disease among subjects who had grown up in poverty followed by a 'high standard of living' as it has been in Norway for the last decades. Together with previous observations in Finnmark ${ }^{12}$ this work supports the opinion that childhood poverty followed by a 'high standard of living' operates, at least partly, as a risk factor for coronary heart disease through conventional risk factors.

The survey was carried out in cooperation with the National Mass Radiography Service, Oslo, Norway and supported by the Norwegian Research Council for Science and the Humanities and the Norwegian Council on Cardiovascular Diseases.

Request for reprints to: Egil Arnesen, Institute of Community Medicine, $\mathrm{Pb} 417$, N-9001 Troms $\emptyset$, Norway.

\section{References}

${ }^{1}$ Forsdahl A. Are poor living conditions in childhood and adolescence an important risk factor for arteriosclerotic heart disease? Br J Prev Soc Med 1977; 31: 91-5.
${ }^{2}$ Forsdahl A. Living conditions in childhood and subsequent development of risk factors for arteriosclerotic heart disease. J Epidemiol Comm Hlth 1978; 32: 34-7.

${ }^{3}$ Thelle DS, Førde OH. The Troms $\varnothing$ heart study. Methods and main results of a cross-sectional study. Acta Med Scand 1976; 200: 107-18.

${ }^{4}$ B jartveit K, Foss OP, Gjervig T, Lund-Larsen PG. The cardiovascular disease study in Norwegian counties. Acta Med Scand 1979; suppl 634: 1-70.

${ }^{5}$ Dixon JW, Brown BM. BMDP-81 Biomedical Computer Programes P-series. Berkely: University of California Press 1981.

${ }^{6}$ Lindberg W, et al. Høyde- og vektundersøkelser hos voksne menn og kvinner. Tidsskr Nor Laegeforen 1956; 76: $362-8$.

${ }^{7}$ Illsley R. Professional or public health. Nuffield Providence Hospital Trust, 1980.

${ }^{8}$ Holme I, Helgeland A, Hjermann I, Lund-Larsen PG, Leren $\mathrm{P}$. Coronary risk factors and socioeconomic status. The Oslo study. Lancet 1976; i: 1396-8.

${ }^{9}$ Marmot MG, Shipley MJ, Rose G. Inequalities in death-Specific explanations of general pattern? Lancet 1984 ; i: $1003-6$.

${ }^{10}$ Holme I, Helgeland A, Hjermann I, Leren $P$, Lund-Larsen PG. Four-year mortality by some socioeconomic indicators: the Oslo study. J Epidemiole Comm Hlth 1980; 34: 48-52.

${ }^{11}$ Westlund $K$, Nicolaysen $R$. Ten years mortality and $\stackrel{\infty}{\omega}$ morbidity related to serum cholesterol. Scand J Clin Lab Invest 1972; suppl 127: 1-24.

${ }^{12}$ Natvig $\mathrm{H}$, Borchgrevink CF, Dedichen J, Owren PA, $\stackrel{\mathrm{D}}{\mathrm{D}}$ Schiøtz EH, Westlund K. A controlled trial of the effect $\subseteq$ of linolenic acid on incidence of coronary heart disease. The Norwegian vegetable oil experiment of 1965-66. Scand J Clin Lab Invest 1968; suppl 105: 1-20. 